\title{
Griginal Acute upper gastrointestinal bleeding in a tertiary care hospital in South India - Have we Improved the outcomes?
}

\author{
Vishnu Prasad NR, Sheikh Manwar Ali, Vijay \\ Ganapathy, Sreenath G S, Suresh Kumar S
}

ABSTRACT

Deparment of Surgery, Jawaharlal Institute of Postgraduate Medical Education \& Research (JIPMER), Puducherry 605006.

Correspondence: Vishnu Prasad NR Email:vprasad285@gmail.com

Background: Since the data on acute upper gastrointestinal bleeding (UGIB) is lacking in many of the institutes of India, this study was taken up to find out the etiology, clinical features and management of patients with acute UGIB. The other aims of the study were to assess the factors associated with re-bleeding and mortality in patients with acute UGIB.

Methods: This study was a hospital-based, prospective observational study, done in all patients presenting with acute upper gastrointestinal bleed, over a period of 18 months from September 2010 to February 2012.

Results: There were 396 patients admitted with upper GI bleed. 17 patients (4.2\%) presented twice with recurrent acute UGIB. The majority of these patients $(52.3 \%)$ were in 41-60 year age group. $35.9 \%$ patients had Oesophageal Varices. The erosive mucosal disease was the commonest cause (29\%) of bleeding in patients with Non-Variceal bleed. Endoscopic variceal ligation was done in $125(30.6 \%)$ patients, sclerotherapy in 9 (2.3\%) patients and 13 (3.3\%) underwent adrenaline injection. Endoscopy failed to control bleeding in $4.5 \%$ of patients. The recurrent rate of bleeding during the hospital stay was $11.9 \%$. Thirty-four (8.6\%) patients' died. 362 patients went home after a mean hospital stay of 6.2 days.

Conclusion: Unlike the evidence from the western studies that peptic ulcer is the commonest cause for acute UGIB; we found varices as the common cause followed by erosive mucosal disease. The recurrent rate of bleeding and mortality were $11.9 \%$ and $8.6 \%$ respectively. Factors found to be significantly associated with recurrent bleeding \& mortality was chronic liver disease and those who needed multiple transfusions. There is scope in improving the outcomes of Acute UGIB.

KEYWORDS: Upper gastrointestinal bleeding; varices; management. 


\section{Introduction}

Acute upper gastrointestinal bleed (UGIB) is a common medical emergency that has a high mortality rate. ${ }^{1}$ Peptic ulcer disease, Oesophageal varices and erosive mucosal disease account for most of the cases, followed by less common causes like Mallory-Weiss tear, malignant ulcer, Dieulafoy's lesion, vascular ectasia, angioma and rare causes like haemobilia, aortoenteric fistula and vasculitis. An astute knowledge of pathophysiology and clinical presentations of acute UGIB enables swift intervention and a reduction in rebleeding and mortality rates. ${ }^{2}$ Studies have been performed worldwide to evaluate the etiology, clinical profile and outcome of patients with acute UGIB. ${ }^{1,2,3,4,5}$ Since such a study was lacking from our institute, we took up this prospective study with the aim to find out the etiology, clinical features and management of patients with acute UGIB and also to assess the factors associated with rebleeding, mortality in our patients. The secondary aim of the study was to look at the deficiency in the existing methods of in managing these patients in our institute.

\section{Methods}

This study was a hospital-based, prospective observational study, done in all patients presenting with acute upper gastrointestinal bleeding (UGIB) to Emergency Medical Services(EMS) from September 2010 to February 2012. Since endoscopic services are with the Department of Surgery for more than two decades in our institute, these patients were managed by Department of Surgery. Patients admitted with acute UGIB constitute nearly thirty percent of the emergency admissions in the Department of Surgery. Patients below 13 years of age, In-patients developing acute UGIB were excluded from the study. The study was approved by the Institute Research Council and Ethics Committee.

Since the study was an observational study to collect the existing data, no attempt was made to make changes in the existing method of managing these patients and an attempt was made to collect all the available data prospectively. After initial resuscitation of the patient, history was obtained regarding the duration, number of episodes of haemetemesis, melaena, haematochezia, previous bleeding episodes. Clinical examination was done to look for pallor, icterus, pedal edema, splenomegaly, hepatomegaly, ascites and signs of liver failure. A nasogastric tube was inserted, and the amount and color of the aspirate were noted. A digital rectal examination was performed look for melaena. Relevant laboratory investigations were done in all patients. Serology for Viral markers was done whenever cirrhosis was suspected. Additional investigations like ultrasound, chest X-ray and computed tomogram (CT) of the abdomen were done whenever necessary and possible. Department of Medicine opinion was taken whenever necessary to rule out the possibility of haemoptysis and patients with haemoptysis were transferred to Department of Medicine.

All patients who presented with the history suggestive of UGIB and haemodynamic instability and those patients whose nasogastric aspirate showed blood were admitted. Patient with history of upper gastrointestinal bleeding with a high risk of bleeding like elderly, associated comorbidity were also admitted. Those patients who were provisionally diagnosed as having portal hypertension received octreotide and antibiotics and those in whom peptic ulcer or erosive mucosal disease was suspected received pantoprazole infusion before endoscopy. Blood and blood products transfusions were given whenever necessary. Those patients who were haemodynamically unstable and who had a haemoglobin $<8$ gm $\%$ and the elderly patients ( $>65$ years) with Haemoglobin $<10 \mathrm{gm} \%$ were given packed cell transfusions. Fresh Frozen plasma transfusion was given in those who had prolonged Prothrombin time. Upper GI endoscopy (UGIE) was done on the next day (within 48 hours). Since UGIE was done the next day, in some of the patients a Sengstaken-Blakemoore tube was inserted especially in whom a diagnosis of portal hypertension was made if they continue to bleed and remain unstable even after starting octreotide infusion. Endoscopic interventions such as banding or sclerosant injection were done for variceal bleeding. If the bleeding was not controlled Sengstaken-Blakemore tube was reinserted or planned for surgical variceal ligation. Endoscopic adrenaline injection was done for bleeding 
peptic ulcer and if not controlled patient was taken up for surgery. Patients whose blood transfusion requirement was more than six units were also considered for surgery. Patients with hypovolemic shock associated with recurrent haemorrhage or a slow continuous blood loss requiring transfusion of more than three units per day were also considered for surgery. The indication and nature of the surgical intervention and intra-operative findings were noted. Any post-procedural or post treatment re-bleeding, morbidity and mortality were also noted.

\section{Definitions}

Those patients having history of alcohol intake for more than 5-10 years and having ultrasound findings of cirrhosis of liver were taken as alcoholic cirrhotics. This was further confirmed by the presence of varices during endoscopy. Those patients who had bled from oesophageal varices, if they had altered echo texture of the liver on ultrasound were taken as having cirrhosis. If they had portal vein thrombosis or cavernomatous transformation of the portal vein, a diagnosis of extra hepatic portal vein thrombosis (EHPVO) was made. If they had periportal echoes, a diagnosis of Non-cirrhotic portal fibrosis was made. Following endotherapy if the bleeding could not be controlled, it was taken as a failure of endotherapy. Re-bleeding was characterized as a new bleeding episode 24 hours after the control of initial bleed. Complications occurring as a result of UGIB or as a result of surgery in these patients were taken as morbidity.

Both descriptive and inferential statistics were used for presenting and analyzing the data. Univariate analysis for the associations between clinical parameters and the morbidity and mortality of UGIB was carried out using the $\chi 2$ test or Fisher's exact test for categorical variables. Continuous variables were compared using Student ' $t$ ' test. A ` ${ }^{`}<0.05$ was considered statistically significant. Multivariate Analysis with Logistic regression to identify independent parameters was performed and is presented with odds ratio and 95\% confidence interval. Statistical analysis was done using SPSS version 16.0.

\section{Results}

There were 396 patients who presented with acute upper gastrointestinal bleeding (UGIB). The mean age of the study population was $47.4 \pm 13.3$ years. The majority of patients $(52.3 \%)$ were in 41-60 year age group. Males clearly outnumbered females with a male: female ratio of 4:1. (Table 1).

Most of the patients presented with bright red vomitus. At presentation, $73.2 \%$ patients had melaena, and $13.6 \%$ had haematochezia. History of NSAID intake was observed in $12.6 \%$. 32.8\% were alcoholics. One hundred and fifty-six patients $(39.4 \%)$ patients presented with shock. 17 patients $(4.2 \%)$ presented twice with recurrent UGIB. Sixty-seven (16.9\%) patients had associated comorbidities at the time of presentation. (Table 2)

We found that 154 (38.8\%) patients had $\mathrm{Hb}<8 \mathrm{gm} \%$. Elevated urea and creatinine were found in nearly $45 \%$ of the patients. Prothrombin time was prolonged in $56 \%$ of the patients. Patients with UGIB due to varices had significantly lower haemoglobin, WBC count and albumin compared with non-variceal bleeders. They also had significantly raised creatinine and total bilirubin. Child-Pugh Grade A, B, C was seen in $48.1 \%, 39 \%$ and $11.7 \%$ of patients with variceal bleed.

Three hundred and eighty-four patients underwent endoscopy out of which $35.9 \%$ patients had Oesophageal Varices while $64.1 \%$ patients had the Non-Variceal bleed. In patients of Variceal Bleed, 96(69.5\%) patients had grade 3 and $40(28.9 \%)$ patients had grade 2 varices. Seventeen $(12.3 \%)$ patients had associated gastric varices. In patients of Non-Variceal bleed, 106 patients had either duodenal or gastric ulcer. Most of the patients with gastric ulcer had an ulcer in the pre-pyloric region. The

Table 1: Age and gender distribution of patients of acute upper gastrointestinal bleeding (Acute UGIB)

\begin{tabular}{l|l|l|l} 
AGE IN & MALE & FEMALE & N=396(\%) \\
YEARS & N=320(\%) & N=76(\%) & \\
\hline$<\mathbf{2 0}$ & $6(1.9)$ & $4(5.3)$ & $10(2.5)$ \\
\hline $\mathbf{2 1 - 3 0}$ & $18(5.6)$ & $10(13.2)$ & $28(7.1)$ \\
\hline $\mathbf{3 1 - 4 0}$ & $63(19.7)$ & $12(15.8)$ & $75(18.9)$ \\
\hline $\mathbf{4 1 - 5 0}$ & $94(29.4)$ & $13(17.1)$ & $107(27)$ \\
\hline $\mathbf{5 1 - 6 0}$ & $79(24.7)$ & $21(27.6)$ & $100(25.3)$ \\
\hline $\mathbf{6 1 - 7 0}$ & $47(14.7)$ & $10(13.2)$ & $57(14.4)$ \\
\hline$>\mathbf{7 0}$ & $13(4.1)$ & $6(7.9)$ & $19(4.8)$
\end{tabular}

Mean age - 47.4+13.3, Male: female ratio - 4:1 
Table 2: Clinical features of acute UGIB patients at admission

\begin{tabular}{l|l}
\hline CLINICAL FEATURES & $\mathbf{N}=\mathbf{3 9 6}(\%)$ \\
\hline Symptoms & \\
\hline Character of vomiting & \\
\hline Bright red & $317(80.1)$ \\
\hline $\begin{array}{l}\text { Coffee ground } \\
\text { Character of stool }\end{array}$ & $79(19.9)$ \\
\hline Melaena & $290(73.2)$ \\
\hline Haematochezia & $54(13.6)$ \\
\hline Other Symptoms & \\
\hline Pain abdomen & $32(8.1)$ \\
\hline Reduced urine output $(<400 \mathrm{ml} / 24 \mathrm{~h})$ & $30(7.6)$ \\
\hline Co-morbidities & $\mathbf{6 7}(16.9)$ \\
\hline Diabetes mellitus & $37(9.3)$ \\
\hline Hypertension & $15(3.7)$ \\
\hline Coronary artery disease & $7(1.8)$ \\
\hline Tuberculosis & $4(1)$ \\
\hline Asthma & $2(0.5)$ \\
\hline Chronic obstructive pulmonary disease & $1(0.3)$ \\
\hline HIV & $1(0.3)$ \\
\hline Risk factors & $130(32.8)$ \\
\hline Alcoholics & $81(20.5)$ \\
\hline Smokers & $50(12.6)$ \\
\hline NSAID intake & $115(29)$ \\
\hline Signs & $156(39.4)$ \\
\hline Tachycardia( $>100 b p m)$ & $58(14.6)$ \\
\hline Shock (SBP<100mm Hg) & $36(9.0)$ \\
\hline Jaundice & $45(11.3)$ \\
\hline Pedal edema & $22(5.55)$ \\
\hline Splenomegaly & $286(72.2)$ \\
\hline Ascites & $110(27.8)$ \\
\hline Character of Nasogastric aspirate & \\
\hline Bright red & \\
\hline Coffee ground & \\
\hline & \\
\hline
\end{tabular}

Majority of the patients were in either in Forrest IIb or IIc. $10.3 \%$ belonged to Forrest 1B. Upper G I Endoscopy could not find the cause of bleed in $10(2.6 \%)$ patients. (Table 3) Twelve patients could not undergo endoscopy. Five patients died during resuscitation phase. Seven patients who had hepatic encephalopathy didn't undergo endoscopy since they were transferred to medicine.
Table 3: Endoscopic diagnosis of patients with acute UGIB

\begin{tabular}{|c|c|}
\hline ENDOSCOPIC FINDINGS & $\mathrm{N}=384(\%)^{*}$ \\
\hline Esophageal Varices (OV) & $138(35.9)$ \\
\hline OV with Gastric Varices & $17(12.3)$ \\
\hline OV with Portal hypertensive gastropathy & $36(26.1)$ \\
\hline Gastric ulcer & $47(12.2)$ \\
\hline Type I & $3(0.9)$ \\
\hline Type II & $4(1.0)$ \\
\hline Type III & $38(9.9)$ \\
\hline Type IV & $2(0.5)$ \\
\hline Duodenal ulcer & $59(15.3)$ \\
\hline Esophagitis & $4(1.0)$ \\
\hline Gastritis & $78(20.3)$ \\
\hline Duodenitis & $22(5.7)$ \\
\hline Gastritis with duodenitis & $8(2.0)$ \\
\hline Carcinoma stomach & $7(1.8)$ \\
\hline Haemosuccus pancreaticus & $2(0.5)$ \\
\hline Vascular malformation & $1(0.2)$ \\
\hline Mallory Weiss tear & $8(2.0)$ \\
\hline Obscure & $10(2.6)$ \\
\hline
\end{tabular}

*12 patients died before endoscopy.

During the resuscitation phase, 154 (38.9\%) patients received packed cell transfusions. Fresh frozen plasma was transfused in $55.8 \%$ of the patients. The mean number of packed cells and Fresh frozen plasma transfused were $2.4 \pm 2.0$ and $6.2 \pm 3.1$ units. Fourteen (3.5\%) patients received massive transfusions. Octreotide infusion was given in 155 (39.1\%) patients before endoscopy but was continued in 124 patients following endoscopy for three days. Injection Pantoprazole was given as an infusion in $56.8 \%$ patients before endoscopy.

Before endotherapy, 92 (23.2\%) patients needed Sengstaken-Blakemoore tube tamponade of bleeding varices. Following endotherapy it was necessary for 9 $(2.2 \%)$ patients. Endoscopic variceal ligation was done in $121(30.6 \%)$ patients, sclerotherapy in $9(2.3 \%)$ patients and $13(3.3 \%)$ underwent adrenaline injection. There was a failure to control bleeding endoscopically in $18(4.5 \%)$ patients. Rebleeding was seen in $47(11.9 \%)$ patients. Following endoscopy it was noted that 134 (33.9\%) patients had Rockall score of more than 3. Due to failure 
of endotherapy Ninepatients with peptic ulcer underwent emergency surgery. The majority of these patients underwent pyloroplasty, under running of bleeder and truncal vagotomy. Surgical morbidity and mortality rate was $77.7 \%$ and $55.6 \%$ respectively in these patients.

Hepatic encephalopathy was the commonest problem $(4.5 \%)$ encountered in these patients. Thirteen (3.3\%) patients developed MODS. Two patients $(0.5 \%)$ developed transfusion reactions. SB tube-related complications were seen in 4 patients. (Table 4) Thirtyfour $(8.6 \%)$ patients died. The majority of these $(67.6 \%)$ were patients with the chronic liver disease. Bleeding duodenal ulcer (17.6\%) was the second common cause of death in these patients. 362 patients went home after a mean hospital stay of 6.2 days. (Table 5)

Univariate analysis showed that patients having comorbidities like Diabetes, hypertension, coronary artery disease, chronic liver disease, Rockall score $>3$, bleeding from varices and those who needed multiple or massive transfusion were at high risk for recurrent bleeding. Patients who had massive haemetemesis, acute renal failure, Rockall score $>3$, chronic liver disease, $\mathrm{Hb}<8 \mathrm{gm} \%$, bleeding from varices, who needed of SB Tube insertion, who needed endotherapy, those who had rebleeding had a significant morbidity \& mortality (Table 6) Patients with chronic liver disease, UGIB from varices and those who needed multiple transfusions, were the ones found on multivariate analysis, to have significant association with morbidity. (Table 7) But chronic liver disease and need of multiple transfusions were the only factors, found on multivariate analysis, to be significantly associated with mortality.

\section{Discussion}

Our study included 396 patients admitted with acute UGIB. The mean age of the patients was 47 years with a male to female ratio of $4: 1$, which is similar to other Indian \& African studies. ${ }^{6,7,8}$ But western studies report a higher age at presentation, ${ }^{9,10,11}$ which is due to elderly population in their community. Eighty percentage of the study population presented with haematemesis, $27.2 \%$ had massive haematemesis, and $39.4 \%$ presented with shock but unlike other studies ${ }^{12}$ pain abdomen was present only in $13 \%$ that is due to higher number of patients with
Table 4: Morbidity of patients with acute UGIB

\begin{tabular}{l|l} 
Parameter & $\mathbf{N}=396(\%)$ \\
Hepatic encephalopathy & $18(4.5)$ \\
\hline Need of Mechanical ventilation & $17(4.3)$ \\
\hline Multi-organ dysfunction syndrome (MODS) & $13(3.3)$ \\
\hline Pneumonia & $8(2.0)$ \\
\hline Acute renal failure (ARF) & $7(1.8)$ \\
\hline Disseminated Intravascular Coagulation (DIC) & $6(1.5)$ \\
\hline Surgical site infections & $3(0.75)$ \\
\hline Deep venous thrombosis (DVT) & $3(0.75)$ \\
\hline Acute respiratory distress syndrome (ARDS) & $2(0.5)$ \\
\hline Transfusion reactions & $2(0.5)$ \\
\hline Iatrogenic pneumothorax & $1(0.25)$ \\
\hline SBT complications & \\
\hline Alar necrosis & $1(0.25)$ \\
\hline Rupture of bulb and rebleed & $1(0.25)$ \\
\hline Aspiration pneumonia & $2(0.5)$
\end{tabular}

Table 5: Mortality of patients with acute UGIB

\begin{tabular}{l|l}
\hline MORTALITY & $\mathbf{N}=\mathbf{3 9 6}(\%)$ \\
\hline Total mortality & $34(8.6)$ \\
\hline Variceal bleed & 25 \\
\hline Non-variceal bleed & 9 \\
\hline Duodenal ulcer & 6 \\
\hline Gastric ulcer & 2 \\
\hline Haemosuccus Pancreaticus & 1
\end{tabular}

Table 6 : Factors found to be significantly associated with morbidity and mortality in Acute UGIB patients following multivariate analysis

\begin{tabular}{l|l|l|l} 
Parameters & Odds ratio & $\mathbf{9 5} \%$ CI & p-value \\
$\begin{array}{l}\text { Patients with } \\
\text { Chronic liver disease }\end{array}$ & 3.524 & $1.037-11.973$ & 0.044 \\
\hline $\begin{array}{l}\text { Bleeding from } \\
\text { Varices }\end{array}$ & 7.272 & $2.599-20.344$ & $<0.001$ \\
\hline $\begin{array}{l}\text { Need of Packed cell } \\
\text { transfusions }\end{array}$ & 5.652 & $2.091-15.276$ & 0.001 \\
\hline
\end{tabular}

variceal bleed in our study. In our study population, 67 patients had co-morbidities with diabetes $(55.2 \%)$ being the commonest co-morbidity. Other studies ${ }^{8}$ report fewer diabetics. 
Following endoscopy in 384 patients, 138 (35.9\%) patients were found to have varices, erosive mucosal disease was seen in $29 \%$, Peptic ulcer in $27.5 \%$ of patients. Thus, Oesophageal varices were the commonest cause for acute UGIB in our patients. This is in contrast to other studies ${ }^{7,10,11}$ on acute upper GI bleeding but similar to study done by Rao et $\mathrm{al}^{6}$ from India. Common causes for UGIB in the order of frequency reported in world literature are the duodenal ulcer (32\%), gastric ulcer (29.7\%), erosions (21.9\%) \& Oesophageal varices $(10.9 \%){ }^{13,14}$ This difference could be explained partly by the referral pattern and partly by the higher prevalence chronic liver disease. The numbers of patients with NonCirrhotic portal fibrosis $(2.7 \%)$ or Extra hepatic portal vein Obstruction $(2.0 \%)$ were small in our study unlike studies from far east or North Indian studies. ${ }^{15,16}$

In our study, 106 patients had bleeding peptic ulcer with a predominance of duodenal ulcer. Of these $65(61.3 \%)$ belonged to Grade I and II of Forrest classification that represents persistent signs of recent hemorrhage. In similar study done by Peetsalu et al., ${ }^{17}$ $80.6 \%$ of patients belonged to Grade 1 and 2 . This may be because of the practice of endoscopy within 24 hours in their study. In our study 47 patients had the gastric ulcer, $6.3 \%$ were type I and $80 \%$ were type III. Type III gastric ulcer behaves like the duodenal ulcer that is common in South India.

In our study, $35 \%$ patients didn't require transfusion with either packed cells or frozen plasma while other series report 20-36 \% ${ }^{18}$ Sengstaken-Blackmore tube (SBT) was used to control bleeding in $92(23.2 \%)$ patients of acute upper GI bleed. In a study done by Mushtaq et $\mathrm{al}^{19}$ where in $24.5 \%$ were in need of SBT. Out of 143 patients who underwent endoscopic intervention, variceal ligation is the major technique used in $63.6 \%$ along with Octreotide, which was used in $86.7 \%$. In a study by Seo et al, ${ }^{20} \mathrm{EVL}$ was done in $90 \%$, but they used both terlipressin and somatostatin to achieve initial hemostasis in $86 \%$.

Rebleeding rates have been reported in the literature to occur in $20-30 \%$ of patients. ${ }^{21,22}$ and is associated with a high risk of mortality. Rebleeding rate in our study group was $14.1 \%$ that is in accordance with the reports in the literature. Rockall score is a clinical risk predictor score for rebleeding and mortality. A score $<3$ was associated with a zero mortality in patients with ulcers or varices. ${ }^{21}$ Rockall scores show a progressive increase in mortality from $2 \%$ to $39 \%$ in patients with a Rockall score $>8.4,22,23$ In our study taking $<3$ as low score and $>3$ as high score, we stratified our study patients $262(66.1 \%)$ as low-risk and $134(33.9 \%)$ as a high-risk group. It was observed that this $33.9 \%$ were found to have high rebleeding, significant morbidity and mortality.

Only $9(2.3 \%)$ out of 396 patients were operated in our study Unlike the reports in the literature where the rate of surgical treatment varies from 10 to $30 \%{ }^{6,14,24} \mathrm{In}$ our study only patients with rebleeding from peptic ulcer were operated and patients with rebleeding from varices, since majority had chronic liver disease, were managed with octreotide infusion and SB tube insertion whenever needed.

Hepatic encephalopathy and MODS were the commonest morbidities seen in our study. All patients who had significant morbidity have had received either Packed Cells or Fresh Frozen Plasma. In a study of Taha et al. on blood transfusion ${ }^{25}$ in patients with moderately severe Nonvariceal UGIB, mortality was higher, following blood transfusion. Whether this reflects selection bias, or an effect of co-morbidity or an effect of transfusion necessitates further studies. In Our study, mortality rates of UGI Bleed patients were $8.6 \%$ that is comparable with the similar studies in the literature. ${ }^{26-28}$ Patients with variceal bleeding had a greater mortality as in other studies than patients with non-variceal bleed. This may be attributed to underlying chronic liver disease.

In our study, most of the recurrent bleeders were having varices. On performing Univariate analysis of recurrent bleeders and non-recurrent bleeders, factors found to significant were those with co-morbidities, Chronic liver disease, large varices, those undergoing endotherapy, those in need of blood transfusion, those who had morbidity and Rockall score $>3$. In Charatcharoenwitthaya et al. $\operatorname{study}^{29}$ by univariate analysis, an increased risk of rebleeding was observed in endoscopic stigmata of recent bleed and blood transfusion.

In a study by Gado et $\mathrm{a}^{30}$, significant mortality were seen in patients of older age ( $>60$ years), among inpatients, major co-morbidities, with chronic liver disease, in those whom early endoscopy was done and in variceal 
bleeders. Our analysis that high Rockall score can have high morbidity and mortality could prove the role of its risk scoring system in UGIB as showed by Vreeburg E M et al. ${ }^{23}$ In the study by Enns et al. ${ }^{9}$ on analysis of patients with morbidity and mortality with those didn't have, the factors found to be significant were massive haematemesis $(>500 \mathrm{ml})$, haematochezia, acute renal failure, associated medical conditions, chronic liver disease, hemoglobin $(<8$ $\mathrm{gm} / \mathrm{dl}$ ), bleeding varices, packed cell/FFP transfusions, SBT insertion, Surgical intervention, rebleeding Postendotherapy Rockall score $>3$. Sugawa et al ${ }^{18}$ has reported hypotension, blood transfusion and varices as factors significantly associated with mortality and they also proposed liver failure and MODS as the major cause of morbidity and mortality.

In our study, chronic liver disease, bleeding from varices and those needed multiple transfusions were the factors found on multivariate analysis, using logistic regression, to be significantly associated with morbidity but only chronic liver disease and need of multiple transfusions were significantly associated with mortality. In another study ${ }^{29}$ multivariate analysis was done concerning mortality, the presence of hemodynamic instability at presentation, a background of liver cirrhosis or disseminated malignancy, a transfusion requirement during admission, and the development of rebleeding, which were statistically significant.

There were many deficiencies in managing these patients. There was no stratification of patients into lowrisk or high-risk at admission based on risk stratification scores. Current recommendations emphasize early risk stratification, by using validated prognostic scales. ${ }^{31}$ It has also been shown that the prokinetics (erythromycin or metoclopramide) before endoscopyincrease the visibility during endoscopy ${ }^{32}$ and reduces the need for repeat endoscopy, but such practice was not existing. Antifibrinolytics have been found to decrease the mortality rate in patients with non-variceal bleed, ${ }^{33}$ but antifibrinolytics were not used in managing any of the patients.

Whenever fundal varix was found, patients were referred to medical gastroenterologist of the same institute or other institutes where facility for glue injection was available immediately. While treating patients with bleeding peptic ulcer endoscopically, only adrenaline was injected, and the recommendation ${ }^{34}$ of dual modality was not followed. This must have resulted in recurrent bleeding in this subgroup of patients.

Though our institute is one of the tertiary care hospitals in this region, there is still a lack of an interventional radiologist. It has been shown in patients with recurrent bleed from peptic ulcer with co-morbidity, mortality following angioembolization is less (3\%) compared with surgery (14\%). ${ }^{35}$ None of the cases of bleeding following surgery or those unsuitable for surgery could be managed by embolization.

Transjugular Intrahepatic Portosystemic Shunt (TIPS) was not done any of the patients, though there were five patients with the chronic liver disease who died during the stage of resuscitation, before endoscopy. There were 9 (11.7\%) of patients with variceal bleed who were in Child $\mathrm{C}$ status who were in need of a TIPS procedure. Following one of the studies at our institute, ${ }^{36}$ which showed a mortality of $46 \%$ following emergency devascularisation procedure, not much attempt is being done for either devascularisation procedure or shunt surgery. The other reason for not attempting such procedures was because majority portal hypertension patients were cirrhotics.

Patients who were admitted on Saturday, endoscope, could not be done on Sunday and was done only on Monday. This "weekend" effect could be one of contributing factors of mortality. The available data shows a reduction in hospital stay, recurrent bleeding and need for surgery and decreased mortality in this subgroup. ${ }^{37,38}$ It is also suggested that improvement in care can be measured by the proportion of patients, in whom endoscopy was done within 24 hours. ${ }^{39}$ In our study endoscopy was done within 24 to 48 hours only and all patient could not undergoendoscopy within 24 hours.

\section{Conclusions}

It can be concluded, unlike the evidence from the west that peptic ulcer is the commonest cause for UGIB; we found varices as the common cause, followed by erosive mucosal disease. The majority of these patients can be treated by a combination of drugs and endotherapy. A Small percentage $(2.3 \%)$ of these patients needs surgery. 
Recurrent bleeding is seen in $14.1 \%$ of these patients. The morbidity and mortality rates are $11.6 \%$ and $8.6 \%$ respectively. Factors found to be significantly associated with morbidity are chronic liver disease, bleeding from varices and those who needed multiple transfusions. But only chronic liver disease and need of multiple transfusions were significantly associated with mortality. There is scope in improving the outcomes of Acute UGIB.

\section{References}

1. Longstreth GF. Epidemiology of hospitalization for acute upper gastrointestinal hemorrhage: a population-based study. Am. J. Gastroenterol. 1995;90(2):206-10.

2. Van Leerdam ME, Vreeburg EM, Rauws EAJ, Geraedts AAM, Tijssen JGP, Reitsma JB, Tytgat GNJ: Acute upper Gi bleeding: did anything change? Time trend analysis of incidence and outcome of acute upper Gi bleeding between 1993/1994 and 2000. Am. J. Gastroenterol. 2003,98:14941499.

3. Yavorski RT, Wong RK, Maydonovitch C, Battin LS, Furnia A, Amundson DE. Analysis of 3,294 cases of upper gastrointestinal bleeding in military medical facilities. $\mathrm{Am}$. J. Gastroenterol. 1995;90(4):568-73.

4. Rockall TA, Logan RF, Devlin HB, Northfield TC. Incidence of and mortality from acute upper gastrointestinal haemorrhage in the United Kingdom. Steering Committee and members of the National Audit of Acute Upper Gastrointestinal Haemorrhage. BMJ. 1995 22;311(6999):222-6.

5. Higham J, Kang J-Y, Majeed A. Recent trends in admissions and mortality due to peptic ulcer in England: increasing frequency of haemorrhage among older subjects. Gut. 2002;50(4):460-4.

6. Rao TH, Pande GK, Sahni P, Nundy S. The management of upper gastrointestinal haemorrhage in a tropical country. Arch Emerg Med. 1991;8(3):169-76.

7. Kashyap R, Mahajan S, Sharma B, Jaret P, Patial RK, Rana S, Pal SL. A Clinical Profile of Acute Upper Gastrointestinal Bleeding at Moderate altitude. JICAM. 2005;6(3):224-8.

8. Elghuel A. The characteristics of adults with upper gastrointestinal bleeding admitted to Tripoli Medical Center: a retrospective case-series analysis. Libyan J Med. 2011,6:6283.

9. Enns R-A, Gagnon Y-M, Barkun A-N, Armstrong D, Gregor J-C, Fedorak R-N. Validation of the Rockall scoring system for outcomes from non-variceal upper gastrointestinal bleeding in a Canadian setting. World $J$. Gastroenterol. 2006;12(48):7779-85.

10. Marmo R, Koch M, Cipolletta L, Capurso L, Grossi E, Cestari R, Predicting mortality in non-variceal upper gastrointestinal bleeders: validation of the Italian PNED Score and Prospective Comparison with the Rockall Score. Am J Gastroenterol. 2010;105(6):1284-91.

11. Romagnuolo J, Barkun AN, Enns R, Armstrong D, GregorJ. Simple clinical predictors may obviate urgent endoscopy in selected patients with nonvariceal upper gastrointestinal tract bleeding. Arch Intern Med. 2007;167(3):265-70.

12. Rathod JB, Shah DK, Yagnik BD, Yagnik VD, Upper gastrointestinal bleeding: audit of a single center experience in Western India. Clinics and Practice. 2011; 1: e132.

13. Faiza A Qari. Major Causes of Upper Gastrointestinal Bleeding at King Abdul Aziz University Hospital (Jeddah). Kuwait Medical Journal. 2001;33(2):127-130.

14. Lakhwani MN, Ismail AR, Barras CD. Upper gastrointestinal bleeding in Kuala Lumpur Hospital, Malaysia. Med J Malaysia. 2000;55(4):498-50.

15. KinghamJ,LevisonD,StansfeldA.Noncirrhotic intrahepatic portal hypertension: A long term follow up study. Quarterly journal of medicine. 1981;50:259-268.

16. Bhargava DK, Dasarathy S, Sundaram KR, Ahuja RK. Efficacy of endoscopic sclerotherapy on long-term management of oesophageal varices: a comparative study of results in patients with cirrhosis of the liver, noncirrhotic portal fibrosis (NCPF) and extrahepatic portal venous obstruction (EHO). J Gastroenterol Hepatol. 1991; 6(5):471-5.

17. Peetsalu A, Kirsimägi U, Peetsalu M. Giant peptic ulcer hemorrhages: epidemiology, treatment, and outcome in the teaching hospital of Tartu. Medicina (Kaunas). 2011;47(1):19-24.

18. Sugawa C, Steffes CP, Nakamura R, Sferra JJ, Sferra CS, Sugimura Y.Upper GI bleeding in an Urban Hospital: Etiology,Recurrence and Prognosis. Ann. Surg. 1990;212(4) 521-6.

19. Cheema M A, Sohail D, ShafiqueM,Ajmal N M, Asad, Mustafa et al, Cheema, Davidsohail, Shafique .Control of acute variceal haemorrhage - a comparison ofoctereotide and balloon temponade. Biomedica. 2004;20:23-7.

20. Seo YS, Kim YH, Ahn SH, Yu SK, Baik SK, Choi SK, et al. Clinical features and treatment outcomes of upper gastrointestinal bleeding in patients with cirrhosis. $J$. Korean Med. Sci. 2008;23(4):635-43. 
21. Hearnshaw SA, Logan RF, Lowe D, Travis SP, Murphy MF, Palmer KR. Acute upper gastrointestinal bleeding in the UK: patient characteristics, diagnoses and outcomes in the 2007 UK audit. Gut. 2011;60(10):1327-35.

22. Vreeburg E, Terwee C, Snel P, Rauws E, Bartelsman J, Meulen J, et al. Validation of the Rockall risk scoring system in upper gastrointestinal bleeding. Gut. 1999;44(3):331-5.

23. Rockall TA, Logan RFA, Devlin HB. Selection of patients for early discharge or outpatient care after acute upper gastrointestinal haemorrhage. Lancet. 1996;347:1138-40.

24. Salimi J, Salimzadeh A, Yazdani V, Ghadimi H, Habibi G Z.Outcome of Upper Gastrointestinal Hemorrhage According to the BLEED Risk Classification: a Two-year Prospective Survey. Bahrain Med Bull. 2007;29.

25. Taha A S, McCloskey C, Craigen T, Angerson W J , Shah A, Morran C. Mortality following blood transfusion for non-variceal upper gastrointestinal bleeding. Frontline Gastroenterology. 2011;2:218-25.

26. M Kaliamurthy, MG Lee, M Mills, T Murphy. Upper Gastrointestinal Bleeding: A Jamaican Perspective. West Indian Med J. 2011;60(3):289-92.

27. Marmo R, Koch M, Cipolletta L, Capurso L, Grossi E, Cestari R, Bianco MA et al. Prediciting mortality in nonvariceal upper gastrointestinal bleeders: validation of the Italian PNED score and prospective comparison with the Rockall score. Amer J Gastroenterol. 2010;105:128491.

28. Hearnshaw SA, Logan RFA, Lowe D. Use of endoscopy for management of acute upper gastrointestinal bleeding in the UK: result of a nationwide audit. Gut. 2010;59:1022-9.

29. Charatcharoenwitthaya P, Pausawasdi N, Laosanguaneak N, Bubthamala J, Tanwandee T, LeelakusolvongS. Characteristics and outcomes of acute upper gastrointestinal bleeding after therapeutic endoscopy in the elderly. World J Gastroenterol. 2011;17(32):3724-3732.

30. Gado AS, Ebeid BA, Abdelmohsen AM, Axon AT. Clinical Outcome of Acute Upper Gastrointestinal Hemorrhage among Patients Admitted to a Government Hospital in Egypt. Saudi J Gastroenterol. 2012;18(1):34-39.
31. Barkun AN, Bardou M, Kuipers EJ, Sung J, Hunt RH, Martel M, Sinclair P; International Consensus Upper Gastrointestinal Bleeding Conference Group.International consensus recommendations on the management of patients with nonvariceal upper gastrointestinal bleeding. Ann Intern Med. 2010;152(2):101-13.

32. Altraif I, Handoo FA, Aljumah A, Alalwan A, Dafalla M, Saeed AM, Alkhormi A, Albekairy AK, Tamim H. Effect of erythromycin before endoscopy in patients presenting with variceal bleeding: a prospective, randomized, doubleblind, placebo-controlled trial. Gastrointest Endosc. 2011;73(2):245-50.

33. Gluud LL, Klingenberg SL, Langholz SE.Systematic review: tranexamic acid for upper gastrointestinal bleeding. Aliment Pharmacol Ther. 2008;27(9):752-8.

34. Marmo R, Rotondano G, Piscopo R, Bianco MA, D’Angella $\mathrm{R}$, Cipolletta L.Dual therapy versus monotherapy in the endoscopic treatment of high-risk bleeding ulcers: a meta-analysis of controlled trials. Am J Gastroenterol. 2007;102(2):279-89.

35. Eriksson LG, Ljungdahl M, Sundbom M, Nyman R.Transcatheter arterial embolization versus surgery in the treatment of upper gastrointestinal bleeding after therapeutic endoscopy failure. $J$ VascInterv Radiol. 2008;19(10):1413-8.

36. Mohanrajda, Hadke NS. A comparison of Shunt \&Nonshunt procedure in the treatment of bleeding esophageal varices. A dissertation submitted to Pondicherry university in partial fulfilment for MS degree in General Surgery, 1991

37. Ananthakrishnan AN, McGinley EL, Saeian K. Outcomes of weekend admissions for upper gastrointestinal hemorrhage: a nationwide analysis. Clin Gastroenterol Hepatol. 2009;7(3):296-302e1.

38. Shaheen AA, Kaplan GG, Myers RP.Weekend versus weekday admission and mortality from gastrointestinal hemorrhage caused by peptic ulcer disease. ClinGastroenterolHepatol. 2009;7(3):303-10.

39. Jairath V, Barkun AN.Improving outcomes from acute upper gastrointestinal bleeding. Gut. 2012;61(9):1246-9. 